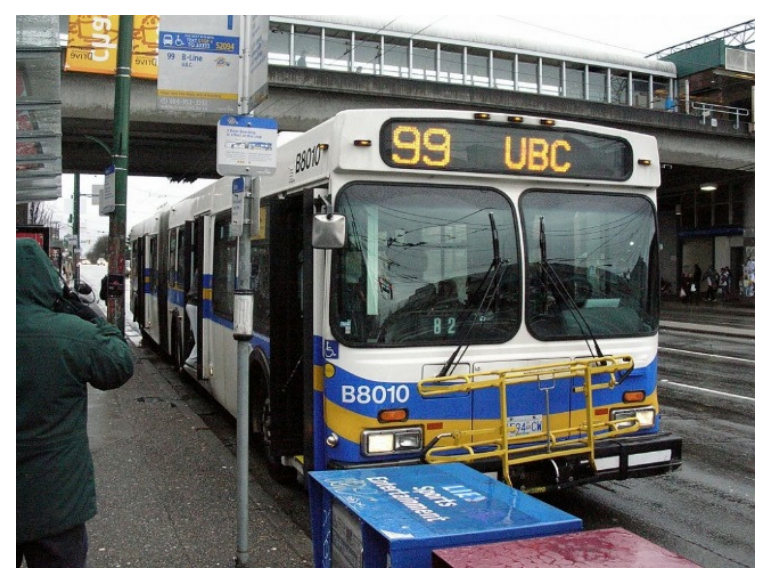

\title{
"Comparing Carbon Dioxide Levels within Urban Transport Microenvironments during Rush Hour and Non-Rush Traffic"
}

\section{PROJECT SUBMITTED IN PARTIAL FULFILLMENT OF THE REQUIREMENTS FOR THE DEGREE OF}

Bachelor of Technology in Environmental Health

$$
\text { By }
$$

Ming Hei (Alan) Leung ${ }^{1}$, Bobby Sidhu ${ }^{2}$

B.Tech in Environmental/ Public Health Inspection, British Columbia Institute of Technology, 2016

(C) Ming Hei (Alan) Leung

\section{BRITISH COLUMBIA INSTITUTE OF TECHNOLOGY}

$$
\text { April } 2015
$$

All rights reserved. This work may not be reproduced in whole or in part, by photocopy or other means, without permission of the author

\footnotetext{
${ }^{1}$ Lead Author, B. Tech Student, School of Health Sciences, British Columbia Institute of Technology, 3700 Willingdon Ave, Burnaby, BC V5G 3H2 ${ }^{2}$ Supervisor, School of Health Sciences, British Columbia Institute of Technology, 3700 Willingdon Ave, Burnaby, BC V5G 3H2
} 
"The Views expressed in this paper are those of the author and do not necessarily reflect the official policy, position or views of BCIT, the Environmental Health Program or its faculty." 


\begin{abstract}
Introduction

Commuters spend countless hours within tightly confined spaces with limited ventilation that may be filled with many contaminants. By analyzing if there is a significant difference between levels of carbon dioxide between rush and non-rush hour conditions, it can be determined if some commuters are subjected to poorer levels of air quality during certain times of the day.
\end{abstract}

\title{
Objectives
}

The primary objective of this study is to understand whether there are significant ventilation deficiencies during rush compared to non-rush hour times in urban transport microenvironments.

\section{Methods}

Analysis of urban transport microenvironments was done using the TSI brand QTrak Indoor Air Quality (IAQ) Monitor to gather data on carbon dioxide at 1-minute intervals on the $99 \mathrm{~B}$-line express bus that runs between Broadway and Commercial Skytrain Station and the Broadway and Cambie Street Skytrain Station.

\section{Results}

A one tailed T-test was done on the NCSS 9 statistical software to compare if rush hour urban microenvironments had significantly higher concentrations of carbon dioxide than when compared to non-rush hour. Statistical analysis determined that since the P-value was well above the alpha level of 0.05 (i.e. $\mathrm{P}<0.05$ ), it gives reason to accept the null hypothesis, which states that rush hour concentrations were not higher than non-rush hour.

\section{Conclusion}

Statistical analysis determined that the overall concentrations of carbon dioxide during rush hour were not significantly higher than non-rush hour times. This result may have been attributed to conditions and factors during data collection that could not be controlled by the researcher. Due to the length of the route, exposure times were found to be within time-weighted averages as set out by the American Conference of Industrial Hygienists (ACGIH), though it was still not within the recommended limit of $1000 \mathrm{ppm}$ as set out by the American Society of Heating, Refrigeration and Air-Conditioning (ASHRAE).

\section{Key Words}

Carbon dioxide; $\mathrm{CO}_{2}$; TSI Q-Trak; Indoor Air; Indoor Air Quality; buses; bus; 99 B-line; CommercialBroadway; Cambie-Broadway; Urban Transport Microenvironments; Rush Hour; Non-Rush Hour 


\section{Acknowledgements}

A very special thanks to Bobby Sidhu for the constant guidance and mentoring that made this

project successful. Additionally, many thanks to Fred Shaw for organizing and preparing the necessary equipment that made sample collection possible. 
Table of Contents

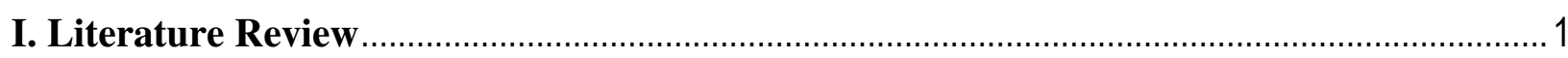

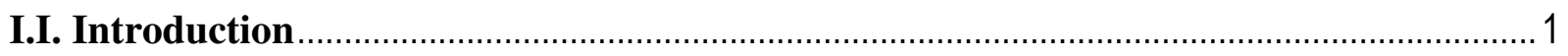

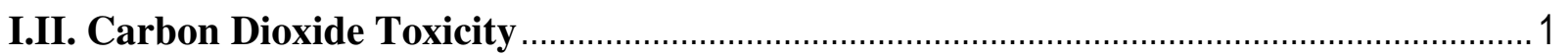

I.III. Carbon Dioxide Uses in Other industries............................................................... 2

I.IV. Carbon Dioxide Emissions Comparing Diesel and Gasoline Engines ......................... 2

I.V. Indoor Air Quality Studies Comparing Different Districts ......................................... 3

I.VI. Effects of Improved Ventilation on Carbon Dioxide Concentrations........................... 3

I.VII. Indoor Air Quality within Urban Transport Microenvironments ............................. 5

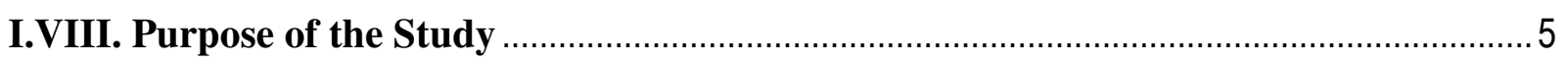

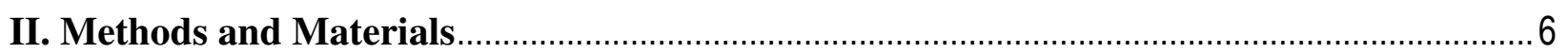

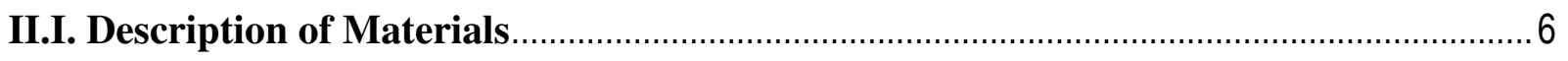

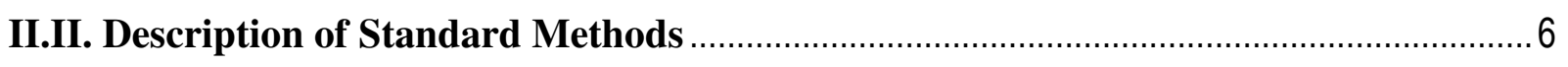

II.III. Reliability and Validity of Measures ................................................................... 7

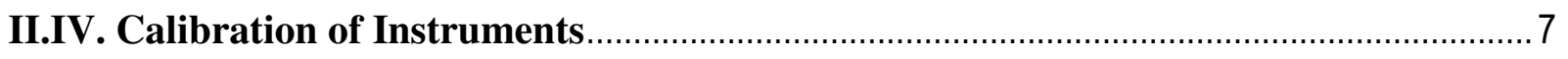

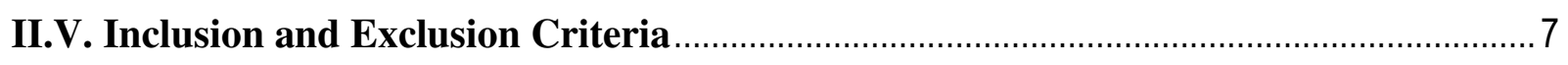

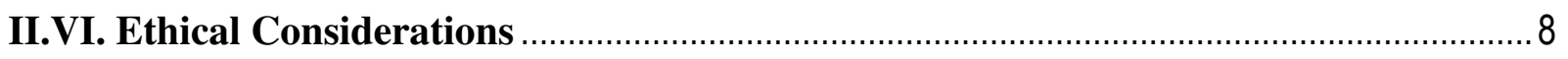

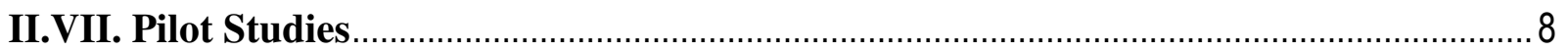

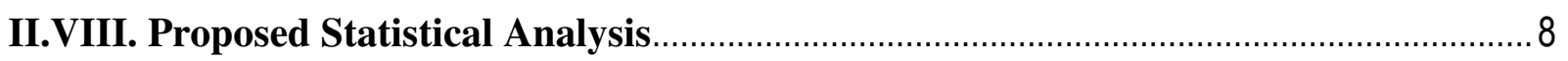

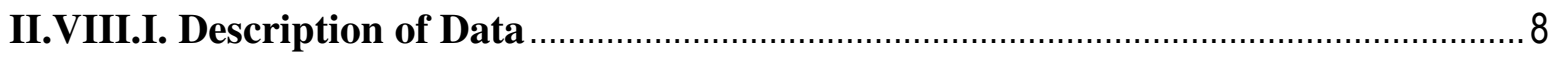

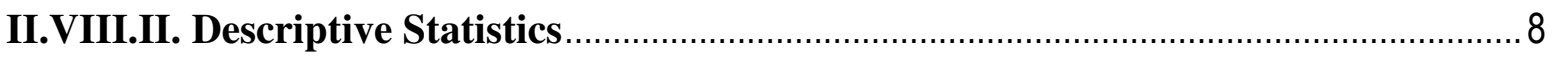

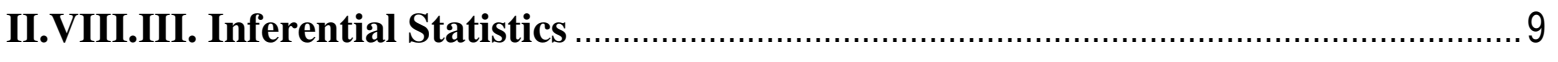

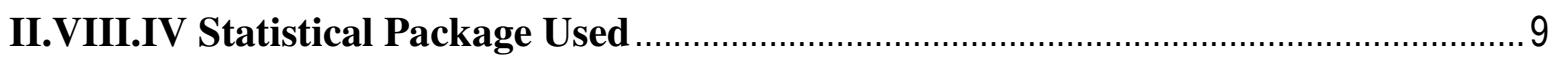

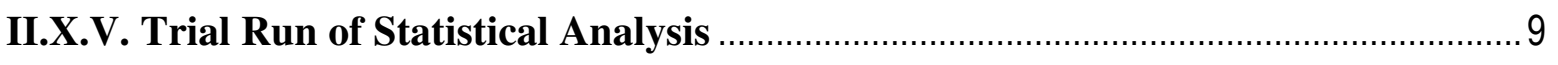

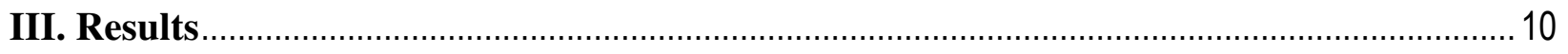

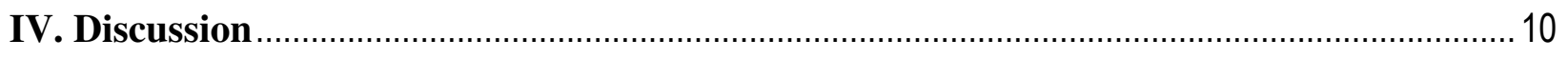

IV.I. Number of Windows Open during Analysis .......................................................... 10

IV.II. Proximity to Bay Doors during Analysis ............................................................... 10

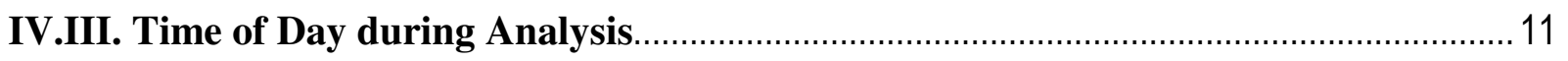

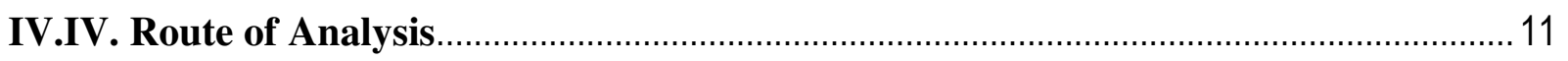

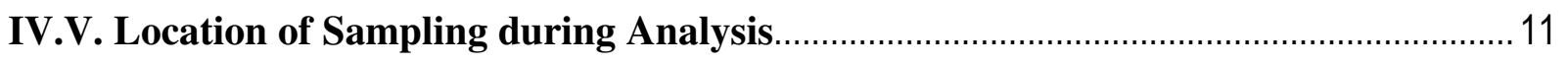

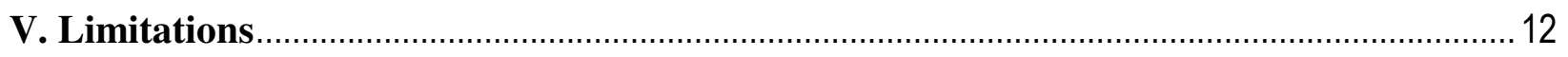

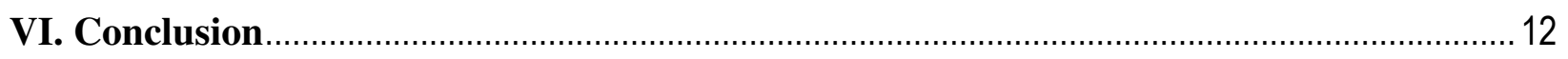

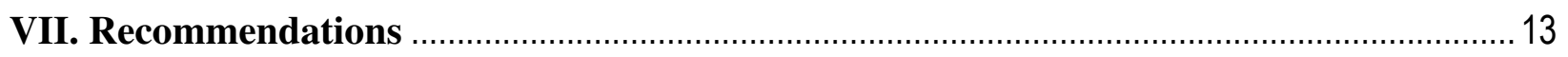




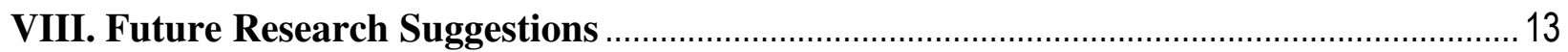

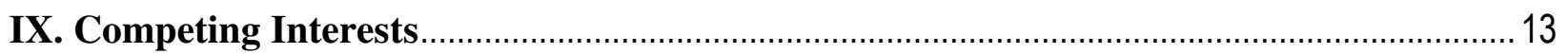

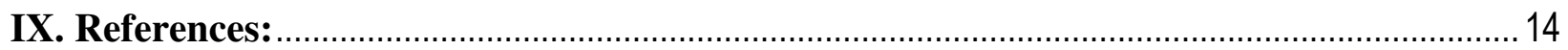

\section{List of Tables}

Table 1. Symptoms from Carbon Dioxide Exposure from High to Low...................................................2

Table 2. Descriptive Statistics for Rush and Non-Rush Hour Samples...................................................9

\section{List of Figures}

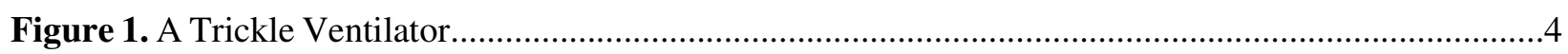

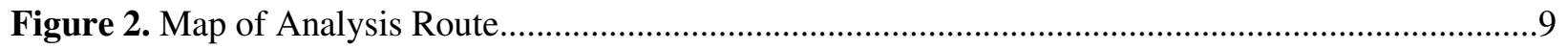




\section{Literature Review}

\section{I.I. Introduction}

Every day, thousands of people in cities such as Vancouver, B.C. spend hours inside buses for the sake of school, work or leisure. Many of these commuters are tightly packed into microenvironments that have limited ventilation. Especially during the rainy or cold winter seasons when windows are kept closed to minimize cold drafts or rain water. Due to the high concentrations of people in such limited spaces during rush hour combined with the lack of proper air ventilation, the eventual build-up of carbon dioxide may present itself as either a nuisance or an indicator of poor air quality.

Carbon dioxide is a colourless, odourless, non-flammable gas that can be emitted as a by-product from human metabolism or from the combustion of fossil fuels (Health Canada, 1987). Therefore, any carbon dioxide being analyzed in the bus cabin will very likely be from a combination of both commuters and the outdoor air environment of the bus. A higher-thanaverage concentration and exposure to carbon dioxide will cause short-term undesirable effects in individuals. Hence, carbon dioxide is useful to use as an indicator for the lack of ventilation in indoor environments (Lee \& Chang, 2000).

\section{I.II. Carbon Dioxide Toxicity}

Carbon dioxide toxicity can manifest in two ways, specifically asphyxiation and chemical changes at the cellular level (Langford, 2005). In the case of asphyxiation, it works by displacement of oxygen atoms inside red blood cells, thereby cutting off a crucial metabolic ingredient for cells (Priestly, 2003). This means that oxygen supply going into cells will decrease, leading to cell death. On the other hand, carbon dioxide also causes "acidosis", a condition where there is an acid-base imbalance in the blood (Nelson, 2000). This condition is caused by having excessive carbon dioxide in the blood leading to formation of carbonic acid, which subsequently dissociates to form hydrogen and bicarbonate ions (Nelson, 2000). The abundance of carbon dioxide in the blood causes a shift in the equilibrium that favors the formation of hydrogen ions, which effectively increases the acidity of the blood (Nelson, 2000). In an effort to compensate for the increase in acidity in the blood, the body increases the breathing rate as an effort to remove excess carbon dioxide (Nelson, 2000).

Carbon dioxide is always present in the environment, but symptoms only manifest when it accumulates to a level significantly higher than normal. At 1-3\% concentration, it can cause a doubling in breathing rate that may be labored, weak narcotic effects, impaired hearing, headaches, and increased blood pressure (Air Products, 1994). At 4-5\% concentration, it can cause a four time increase in breathing rate, symptoms of being intoxicated, and feelings of being slightly choked (Air Products, 1994). At 5$10 \%$ concentration, there is a noticeable and characteristic sharp smell, labored breathing, headaches, blurry vision, tinnitus, and usual loss of consciousness (Air Products, 1994). Finally, if levels reach $50-100 \%$ concentration, prolonged exposure has a very high potential to lead to death (Air Products, 1994). However, levels of carbon dioxide within buses would never reach these concentrations unless there is a drastic increase in commuters, a malfunctioned air-exchange system with no windows available, heavy outside traffic, or any combination of those factors.

The time-weighted average threshold value, based on an 8-hour work day and 40 hours a week for carbon dioxide, is 5000 ppm (ACGIH, 1971). On the other hand, the short term exposure limit of 15 minutes is $30,000 \mathrm{ppm}$ (ACGIH, 1971). It must be noted that these threshold levels are only for workers working closely with carbon dioxide, and that if exposure times are kept within their limits, there will be no health effects.

Carbon dioxide is not considered by Worksafe BC (2014) to be a toxic air contaminant in workplaces. However, it is commonly used in establishing whether indoor air environments are sufficiently ventilated (Worksafe BC, 2014). It states that unless indoor concentrations of carbon dioxide are less than $650 \mathrm{ppm}$ above the ambient levels, there needs to be no reason for an assessment on the ventilation rate (Worksafe BC, 2014). Additionally, previous ASHRAE standards (62-1989) has considered that 1000 ppm of carbon dioxide is the maximum 
acceptable concentration recommended for indoor environments.

As mentioned previously, though carbon dioxide inside bus cabins are highly unlikely to ever reach concentrations that would be considered hazardous to human health, it does have standards in industries working closely with the gas. These standards can act as a reference point for this study in case the worst case scenario is experienced. Table 1 below, describes the typical symptoms that are seen when concentrations of carbon dioxide reach hazardous levels.

Table 1. Symptoms from Carbon Dioxide Exposure from High to Low

\begin{tabular}{|c|c|}
\hline $\begin{array}{l}\text { \% Carbon } \\
\text { Dioxide }\end{array}$ & Symptoms \\
\hline $\begin{array}{c}2-3 \\
(20,000- \\
30,000 \mathrm{ppm})\end{array}$ & $\begin{array}{l}\text { Shortness of breath, deep } \\
\text { breathing }\end{array}$ \\
\hline $\begin{array}{c}5 \\
(50,000 \\
\mathrm{ppm})\end{array}$ & $\begin{array}{l}\text { Breathing becomes heavy, } \\
\text { sweating, pulse quickens }\end{array}$ \\
\hline $\begin{array}{l}7.5 \\
(75,000 \\
\text { ppm) }\end{array}$ & $\begin{array}{l}\text { Headaches, dizziness, } \\
\text { restlessness, breathlessness, } \\
\text { increased heart rate and blood } \\
\text { pressure, visual distortion }\end{array}$ \\
\hline $\begin{array}{c}10 \\
(100,000 \\
\text { ppm })\end{array}$ & $\begin{array}{l}\text { Impaired hearing, nausea, } \\
\text { vomiting, loss of } \\
\text { consciousness }\end{array}$ \\
\hline $\begin{array}{c}30 \\
(300,000 \\
\mathrm{ppm})\end{array}$ & Coma, convulsions, death \\
\hline
\end{tabular}

Source: Air Quality Science IAQ Resource Center (Aerias) (2005)

\section{I.III. Carbon Dioxide Uses in Other industries}

Carbon dioxide can be useful in many industrial applications, but it must first be chemically generated. Carbon dioxide is a byproduct that is formed from ammonia and hydrogen production (Topham, Bazzanella, Schielbahn, Luhr, Zhao, Otto \& Stolten, 2005). Other ways to generate carbon dioxide are still employed, but the aforementioned method is the most efficient and financially feasible one (Topham et al., 2005).
Examples of industries that utilize carbon dioxide include the following: biotechnology, healthcare, food and beverage, recreational and leisure, agricultural, and energy (Praxair, 2014). Regarding public health, compressed carbon dioxide gas can specifically be used in both the pool and food service environment. Instead of using highly corrosive compounds such as hydrochloric acid to adjust the $\mathrm{pH}$ balance needed for the disinfection efficacy of pools, carbon dioxide can be used as an advantageous alternative (Goma, Guisasola, Taya, Baeza, Baezam, Bartroli, Lafuente \& Bartroli, 2010). Meanwhile, fountain drinks in food service establishments are commonly dispensed to patrons by combining potable water with the already combined drink syrup and carbon dioxide. Though, it must be mentioned that when carbon dioxide is dissolved into water, carbonic acid forms and lowers the $\mathrm{pH}$. This may especially become problematic if there is no backflow prevention on fountain drink dispensing devices that connect to a water source using copper piping. The reason for this is because a decreased $\mathrm{pH}$ can cause copper to leach into the water supply and potentially lead to toxicity if a high enough concentration permits (Washington State Department of Health, 2009).

\section{I.IV. Carbon Dioxide Emissions Comparing Diesel and Gasoline Engines}

Levels of carbon dioxide being generated by non-biological sources must also be considered. An alternative way that carbon dioxide can skew results of this study is from the burning of fossil fuels within the immediate environment. Two predominant engine types that are used on the roads include gasoline and diesel. Both types ignite fuel and oxygen together to produce exothermic reactions inside the engine, thereby moving pistons that power a crankshaft to generate the rotary motion needed to turn the wheels of an automobile forward (Brain, 2014). Due to the increased efficiency of the diesel engine when compared to gasoline types, less fuel is used overall (Brain, 2014). For this reason, diesel engines generally produce less carbon dioxide than when compared to gasoline engine types. 
In the United States, it was estimated in 2013 that 1,095 million metric tons of carbon dioxide was generated from gasoline vehicles, while 427 million metric tons of carbon dioxide were from diesel vehicles (US Energy Information Administration, 2014). An obvious drawback to this statistic may be that gasoline engine vehicles are higher in demand when compared to diesel vehicles. Alternatively, there may be more gasoline engine vehicles on the road when compared to diesel ones. A comparison of the two engine types is pertinent to this study due to the fact that a portion of the analyzed carbon dioxide within the cabin may be from the traffic around the bus or from the bus itself.

\section{I.V. Indoor Air Quality Studies Comparing Different Districts}

An indoor air quality study spanning three months during the winter was performed on several Hong Kong schools in differing districts of the city. It was shown that the outdoor concentrations of carbon dioxide remained relatively consistent at the range of $400-450 \mathrm{ppm}$ and no differences were seen in differing districts (Lee \& Chang, 2000). However, when levels of carbon dioxide were analyzed indoors, it was seen that there were significant differences when differing modes of ventilation were taken into consideration (Lee \& Wang, 2000). When comparing a school that used water cooling towers to ones that used ceiling fans for ventilation, it was shown that the use of air conditioning caused higher fluctuations in indoor carbon dioxide levels, reaching a maximum concentration of 5900 ppm (Lee \& Wang, 2000). Though, the researchers did note that in this particular school, windows and doors were kept closed during class times when the analysis took place (Lee \& Wang, 2000). Effectively, it could be surmised that when there was a lack of natural ventilation, there was an increase in carbon dioxide concentrations noticed indoors. A main limitation to this study that could have potentially lead to biased results was that the number of students per classroom of each school could not be standardized consistently.

Comparatively, another air quality monitoring study was done in two chosen cities of Korea: Seoul and Taegu (Baek, Kim \& Perry,
1997). Similar to the study done in Hong Kong, indoor air environments were analyzed and compared to outdoor levels in differing districts. The Korean study differed from the Hong Kong study in that: studies were not done in schools, analyses were done in specified times of the day, and the study was conducted in both summer and winter to take into account seasonality. The researchers concluded that the indoor concentrations of carbon dioxide were significantly higher in commercial districts and that it may have been attributable to the relatively heavier traffic conditions in these areas (Baek et al., 1997). Another point of interest was that when numerical results were compared to questionnaires from restaurants, offices and residencies that were analyzed, it was determined that indoor factors like combustion of fuels for warmth and increased human occupancy had a bigger impact on indoor air quality than the outdoor air quality itself (Baek et al., 1997).

In essence, both studies showed that indoor air environments were always higher in carbon dioxide concentrations than outdoor environments. A key difference between the studies was that one was done to identify any differences in carbon dioxide concentrations between schools in differing districts, while the latter, instead, compared commercial building environments between differing districts. Though the results from each study contradicted each other, two distinct factors stood out regardless of the outdoor air environment and what district the analysis took place: poor ventilation and increased human occupancy dramatically increased the indoor air concentration of carbon dioxide.

\section{I.VI. Effects of Improved Ventilation on Carbon Dioxide Concentrations}

In a report on the association between ventilation rates and carbon dioxide concentrations by Seppänen, Fisk and Mendell (2004), several limiting factors were considered even before the implementation of a more effective ventilation system to improve indoor air quality. The first factor is that carbon dioxide is often not in a steady state during the time of analysis (Seppänen et al., 2004). This implies that concentrations of carbon dioxide fluctuate 
through time and therefore would be subject to over or underestimation. Secondly, the assumption that there is a uniform amount of carbon dioxide throughout the analyzed area is a dangerous one (Seppänen et al., 2004). Depending on the type of activity, diet, weight, and number of occupants in certain areas, there may be an unequal distribution of carbon dioxide that will effectively give the analyzer a biased representative sample (Seppänen et al., 2004). Though the use of carbon dioxide may have its limitations as an indicator for indoor air quality, it can still act as a baseline level for the overall effectiveness of the ventilation system. When multiple indoor air quality studies were analyzed by Seppänen et al. (2004), it was found that there was an increased prevalence of respiratory illness when there was a decrease in the ventilation rates. Essentially, if the ventilation rates are increased, there is an overall increase in the general health of occupants.

A study comparing the effects of improved ventilation was assessed using the same group of workers over the span of three years (Bourbeau, Brisson \& Allaire, 1997). However, instead of being just a numerical study that analyzed contaminant concentrations relating to poor ventilation, additional questionnaires were also given out (Bourbeau et al., 1997). The presence of any of the following symptoms in workers included: Nose and throat irritations, eye irritations, respiratory irritations, skin irritations, headaches, fatigue, and difficulty concentrating (Bourbeau et al., 1997). It was found that when a new ventilation system was used, there was a $40 \%$ to $50 \%$ decrease in the prevalence of most symptoms in the first six months (Bourbeau et al., 1997). Relatedly, under the new ventilation system, the concentrations of carbon dioxide decreased from $810 \mathrm{ppm}$ in the first year to 601 ppm in the third (Bourbeau et al., 1997). As can be seen in this study, the decrease of carbon dioxide in the workplace had a positive correlation to the increase of ventilation rate and also an increase in overall satisfaction by occupants.

In a study done comparing the effects of using natural, trickle and purge ventilation in a London classroom, it was shown that trickle ventilation was better at reducing carbon dioxide while also allowing for the best thermal comfort and energy savings (Griffiths \& Eftekhari, 2007). When the classroom was naturally ventilated, it was found that though this method reached the lowest maximum carbon dioxide concentration of $1770 \mathrm{ppm}$, it caused significant thermal discomfort to students (Griffiths \& Eftekhari, 2007). When classrooms were purged with fresh air for 10 minutes twice in timed intervals during the school day, it was found that though it was effective in reducing carbon dioxide concentrations by approximately $1000 \mathrm{ppm}$, it also caused a $3{ }^{\circ} \mathrm{C}$ decrease in ambient room temperature (Griffiths \& Eftekhari, 2007). Additionally, purging the room with fresh air only appeared to be a temporary solution as concentrations of carbon dioxide quickly rose thereafter (Griffiths \& Eftekhari, 2007). In order to set a control for this study, ventilation modes for this classroom were then left alone by the researchers and instead left to the control of the occupants. When this was done, it was found that carbon dioxide concentrations fluctuated wildly with lower minimum concentrations but had relatively similar maximums as other methods (Griffiths \& Eftekhari, 2007). In figure 1 below is a picture of a trickle ventilator.

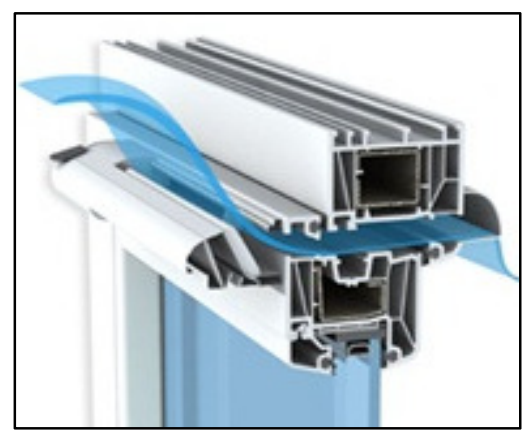

Figure 1.

A Trickle Ventilator

Source: www.1afenster.com

As demonstrated by researchers in the above studies, though adequate ventilation is necessary in reduction of carbon dioxide within indoor spaces, each differing mode of ventilation also has its own set of advantages and disadvantages. The main disadvantage is the reduction of warmth within these spaces, especially during cold winter months. When 
comparing the indoor spaces within bus cabins to those of institutional, residential and commercial buildings, both environments struggle to balance thermal comfort and being properly ventilated. For this reason, since the trickle ventilator appeared to reduce overall carbon dioxide concentrations without drastically compromising thermal comfort, it may also be feasible for installation into buses due to it being energy saving and cost effective.

\section{I.VII. Indoor Air Quality within Urban Transport Microenvironments}

When the indoor air quality within buses in Taiwan was assessed, it was found that depending on the type of route that the buses took, more contaminants ended up accumulating inside the cabin (Hsu \& Huang, 2009). The routes analyzed in this study included buses that drove on local streets with more frequent stops and buses that drove on longer routes with less stopping involved such as highways (Hsu \& Huang, 2009). When a statistical analysis was done, it was found that the cabins of buses that took the longer bus routes had significantly less carbon dioxide than ones that took shorter routes (Hsu \& Huang, 2009). The researchers postulated that this result may have been due to the constant opening and closing of cabin doors that allowed for outdoor air contaminants to enter (Hsu \& Huang, 2009). A second factor that was also considered in this study was the level of carbon dioxide during seasonal variations. It was found that carbon dioxide concentrations were higher during the summer months when compared to winter. Again, the researchers attributed this trend to the indoor air microenvironment being continually exposed to outdoor air contaminants from the heightened frequency of commuters during the summer months (Hsu \& Huang, 2009).

In a meta-analysis done on air quality within urban transport microenvironments, it was determined by Kaur, Nieuwenhuijsen and Colvile (2007) that the following key variables affected a commuter's personal exposure to different pollutants: personal/ individual factors, mode of transport factors, traffic factors, and meteorological factors. Firstly, Kaur et al. (2007) mentions that if a person makes a conscious decision to situate themselves into the breathing zone that is the most contaminated, they will also be the most heavily exposed to said contaminants. Secondly, the researchers mention that any intrinsic factors within the vehicle, such as ventilation systems and bus speed, will also cause differing levels of contaminant exposure to the commuter (Kaur et al., 2007). Thirdly, traffic conditions such as road conditions and number of traffic interruptions also became another factor associated with rider exposure to contaminants (Kaur et al., 2007). Lastly, meteorological factors such as wind speed and in-vehicle concentrations of contaminants (Kaur et al., 2007).

Since there is evidence to suggest that the outdoor traffic environments greatly affect the indoor concentrations of carbon dioxide, the opening of windows and doors will be considered to be a major limitation to this study. For this reason, analysis must take place in a location that has as little contribution from outside sources as possible. As well, additional variability will also come from the number and types of riders on the bus. For example, an unrepresentative sample would be taken if a group of athletes that just got off practice were to surround the Q-Trak at only a certain area of the bus.

\section{I.VIII. Purpose of the Study}

Commuters are utilizing urban transport systems and inevitably subjecting themselves to a variety of contaminants found in such microenvironments. There are many contaminants, including particulate matter, ultrafine particulate matter, volatile organic compounds, carbon monoxide, carbon dioxide and bio-aerosols. Though, if there is a need for assessing the indoor air, then carbon dioxide is most often used due to it being found naturally in the outdoor air, but also found in large quantities in the indoor environments. Contributions of carbon dioxide to the outdoor air environment include the burning of fossil fuels as well as from people. Meanwhile, the contributions to indoor air carbon dioxide include the outdoor air environment as well as people within. Therefore, examples of factors that may affect this urban transport microenvironment include traffic conditions around the bus, the bus route itself, the ventilation system, the quantity of riders and the concentration of riders and their metabolic rates. 
Since the ASHRAE, (1989) has recommended that indoor air environments should only have a maximum carbon dioxide concentration of 1000 ppm, then it is curious to see if these microenvironments actually stay within this limit. Therefore, the objective of this study is to compare the carbon dioxide concentrations of these urban transport microenvironments during the rush and non-rush hour periods, so as to better understand if recommended levels are maintained.

\section{Methods and Materials \\ II.I. Description of Materials}

The materials needed for carbon dioxide analysis can be broken down into two general categories: instrumentation needed at the site of analysis and instrumentation needed for data analysis. At the site of analysis, the TSI Q-Trak Indoor Air Quality (IAQ) monitor will be required. The reason this is used is to calculate the various concentrations of carbon dioxide within bus cabins. There will be an attempt to hold it near the breathing zone at all times, but this may change depending on the conditions of the bus, especially during rush hour times. The data gathered from the Q-Trak IAQ Monitor will be uploaded onto the TSI TrakPro Data Analysis software and then transferred onto NCSS 9 for further statistical analysis.

\section{II.II. Description of Standard Methods}

Before any analysis can begin, there needs to be a clear definition of the terms "rush hour" and "non-rush hour". According to
Merriam-Webster (2014), the term "Rush Hour" is defined as a time of day during the early morning or late evening when commuters are either leaving home for work/ school or coming home from work/ school. This is also a time when the traffic on roads is at its busiest. Therefore, "non-rush hour" can easily be defined as any time of the day when commuters are not going to work/ school from home or vice versa. Using the definition of what the phrase "rush-hour" pertains to, the carbon dioxide analysis can take place during two crucial times of the day: in the early mornings and in the late afternoons. Since commutes to work or school can generally begin anywhere from 3:00 to 6:30 pm, these ranges will be considered the window of opportunities for rush hour carbon dioxide analysis. Conversely, any non-rush hour measurements will be performed any time in between the two defined rush hour times.

Since the environment used for analysis will be in a bus cabin of the 99 B-line, it would make the most sense to measure the differing levels of carbon dioxide from the start, Broadway Station, to the end, the University of British Columbia bus loop. Unfortunately, though this situation would be considered ideal, it must be mentioned that it takes approximately 40 minutes from start to finish for one sample. For time constraint reasons, the end location will be changed from the University of British Columbia bus loop to Cambie Street SkyTrain station. A map of the route of analysis is shown below in Figure 2.

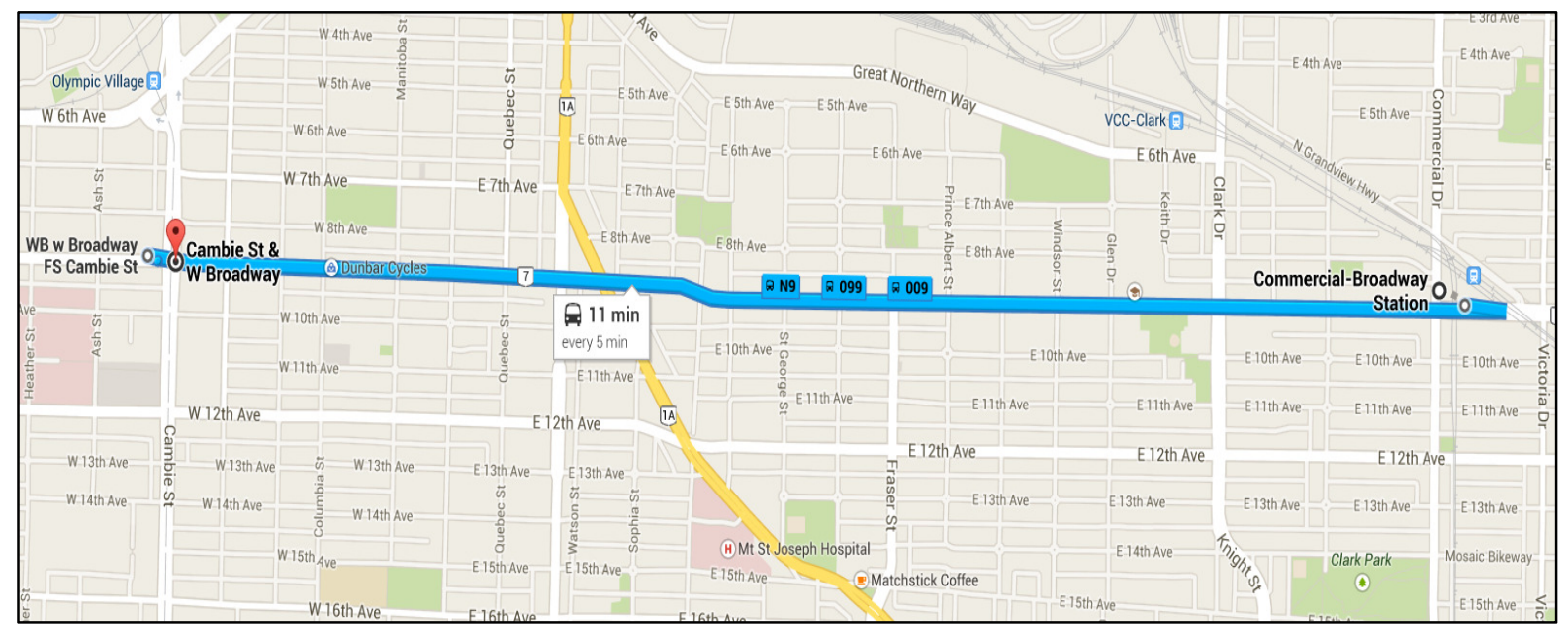

Figure 2. Map of Analysis Route 
Before analysis begins, the Q-Trak IAQ monitoring instrument must first be calibrated. The reason why the Q-Trak must be calibrated beforehand is because it allows for the same baseline for every time a new measurement is done. In essence, it allows for the instrument to increase in validity and reliability. Position the device into the breathing range of the ordinary commuter. When there, it is important not to deviate too much from that location during analysis. This remains to be a crucial step in the analysis due to the chances of increasing variability. Factors such as opened windows, being too close to doors where riders arrive and depart and being too close to other riders may skew results. When it is decided where the analysis will take place, note the time and particular conditions that are present, such as windows opened, the approximate number of commuters, and the weather conditions. This is also an important step because it allows for there to be context to the study. For example, it will allow for readers to interpret that perhaps during particular days when it is raining, the concentrations of carbon dioxide are significantly higher than when it is not. Have the Q-Trak IAQ monitor record a measurement at every 1 minute interval. Be sure to start it when the bus begins to leave the either stops. Since a "sample" is considered to be a full analysis from start to finish and vice versa, and not just one of the many data points from one sample, there needs to be at least several full days of analysis to fulfill this requirement. Once all samples have been taken, there needs to be a subsequent data analysis. Use NCSS 9 program to analyze the data. Since it is assumed that rush hour concentrations of carbon dioxide will be higher than non-rush hour, a onetailed T-test will be used instead of a two-tailed one. It is also assumed that the data will be normal and have equal variances.

\section{II.III. Reliability and Validity of Measures}

With all experiments that require the use of raw data, there needs to be a consideration of both reliability and validity of measures. According to Long and Johnson (2000), reliability refers to the consistency in which data can be effectively collected by different observers. Hence, if this experiment is identically carried out by another researcher and the results are almost identical, then it can be said there is high reliability in the methods of this experiment. Though, in order for there to be higher reliability within measurements of the experiment itself, the researcher must be consistently administer the same protocols for every sample taken. In the case of this experiment, factors like calibrating the instrument before every sample, sitting in approximately the same areas of the bus, placing the device in the same breathing zone, doing the analysis on the same route and on the same time of day will all contribute to heightening the reliability of measures.

On the other hand, validity refers to whether the instrument measures what it is supposed to measure (Long \& Johnson, 2000). For example, if an instrument measured 200 ppm of carbon dioxide when the actual measure is 300 ppm, then the instrument can be said as lacking in validity. Some ways of increasing validity in this experiment include calibrating the equipment with a known standard. This will ensure if the instrument is truly reading with what it is supposed to be reading.

A main way of testing the validity and reliability of the methods is through the use of a min-trial. When this is done, the majority of faults and limitations of the experiment can be fixed and if there are any that cannot be avoided, at least acknowledged.

\section{II.IV. Calibration of Instruments}

As mentioned in the above section, calibration needs to be done to ensure reliability and validity of measures. One of the main advantages of the TSI Q-Trak is that the calibration can easily be done. The instruments needed are the TSI Q-Trak and the TSI calibration probe that is attached in place of the detector probe (TSI, 2012). After that is done, the calibration program can be initiated and performed.

\section{II.V. Inclusion and Exclusion Criteria}

Analysis of carbon dioxide for this experiment will take place only on the 99 B-line express that runs from Broadway and Commercial to Broadway and Cambie, and vice versa. All measurements will be taken by using only the TSI Q-Trak IAQ monitor. As described 
in greater detail in "Description of Standard Methods", the times to analyze will occur only during recognized rush hour periods such as in the mornings and late in the afternoons when commuters are going to work/school from home or vice versa. The control will be non-rush hour periods, which is defined as any time that is not considered to be rush hour.

\section{II.VI. Ethical Considerations}

When conducting experiments, especially ones that involve live animal subjects such as with animals or humans, ethics must be considered. In other words, what is morally correct and socially acceptable must be followed. Drummond (2009) explains that studies should be done in a way so that results can be presented without causing unnecessary pain and suffering to its participants. He states that ethical standards should not be simply regulated, but also followed (Drummond, 2009). Since this specific study involving carbon dioxide in a bus carriage does not involve using any live subjects, there need not be a consideration of ethics as there will not be any possibility of inflicting any pain or suffering.

\section{II.VII. Pilot Studies}

A pilot study was conducted so that any variables such as time, cost, and feasibility of the experiment, was improved upon prior to this fullscale experiment. An advantage to doing a pilot study is that there is a possibility of improving the experiment's reliability as well. For example, perhaps the pilot study will show to the researcher that sitting in a particular location of the bus will yield highly variable data with many outliers. If this is the case, then the methodology can be changed so that this can be prevented. Therefore, this will ensure that the reliability of the sample collection will increase.

\section{II.VIII. Proposed Statistical Analysis \\ II.VIII.I. Description of Data}

The concentrations of carbon dioxide will be measured simultaneously by the TSI QTrak IAQ monitor in one minute intervals throughout the analysis. Measurements will begin as the 99 B-Line bus departs from either the Broadway and Commercial stop or the Broadway and Cambie stop. Since this is not data gathered from categorization, it will therefore be considered to be numerical and not ordinal or nominal data. To be more specific, the concentrations of carbon dioxide are considered to be continuous numerical data since it cannot be simply counted, but exists within a range.

\section{II.VIII.II. Descriptive Statistics}

For this specific analysis, a mean concentration of carbon dioxide within bus cabins for each sample during rush and non-rush hour times were taken using 1 minute intervals by the Q-Trak IAQ monitor. This data was uploaded into the TSI TrakPro software so that it could be uploaded into NCSS 9 for further data analysis. The means from each sample collected in their respective traffic conditions were used to determine if there was a significant difference. 


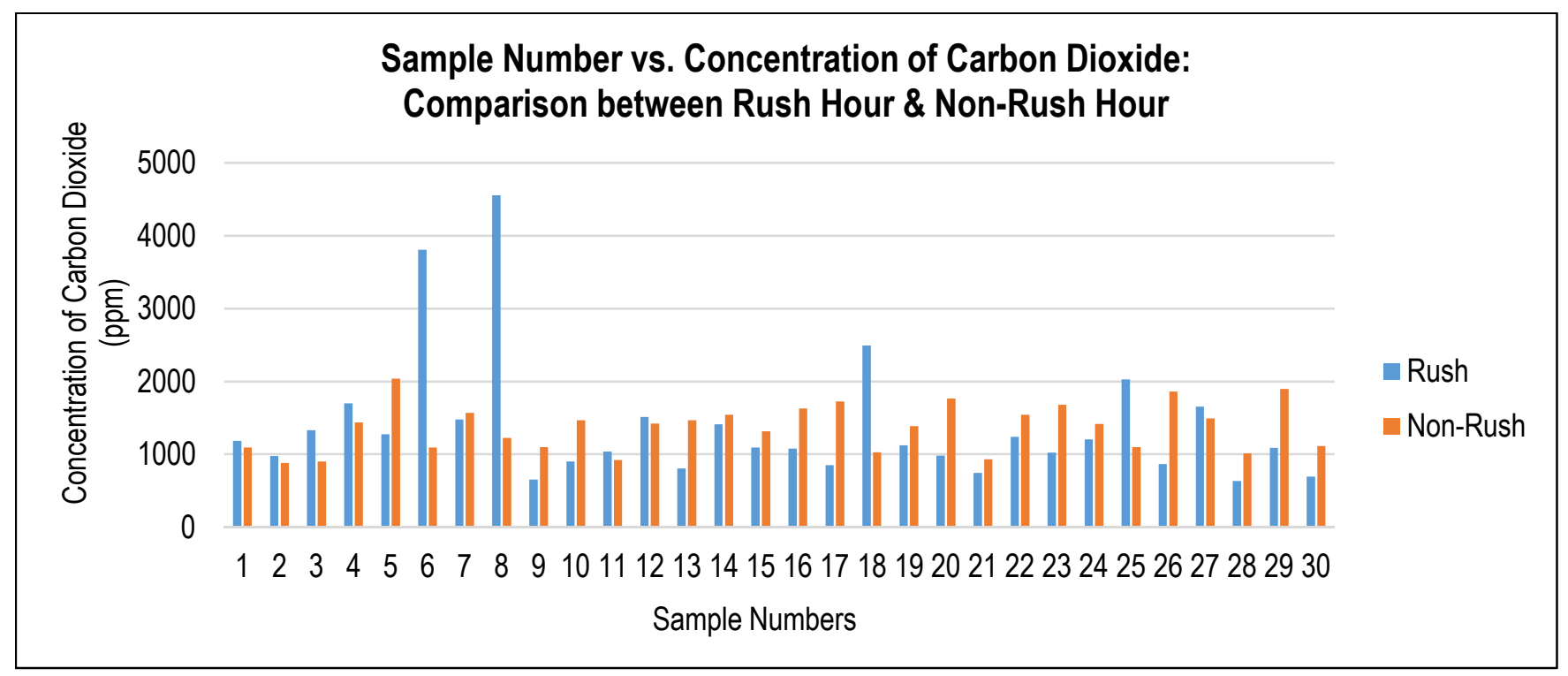

Figure 2. A Comparison between Rush Hour and Non-Rush Hour

Shown above is Figure 2 and below is Table 2 . Table 2 shows the descriptive analysis of both rush and non-rush averages, while Figure 2 shows a comparison of these data averages in graphical form.

Table 2. Descriptive Statistics for Rush and Non-Rush Hour Samples

\begin{tabular}{|c|c|c|}
\hline & Rush & Non-Rush \\
\hline Mean & 1381 & 1380 \\
\hline Median & 1108 & 1263 \\
\hline Mode & N/A & N/A \\
\hline Range & 3920 & 1157 \\
\hline Minimum & 635 & 881 \\
\hline Maximum & 4555 & 2038 \\
\hline $\begin{array}{c}\text { Standard } \\
\text { Deviation }\end{array}$ & 158.7 & 61.5 \\
\hline
\end{tabular}

\section{II.VIII.III. Inferential Statistics}

The specific test intended to be used to compare the concentrations of carbon dioxide within rush hour and non-rush hour times is the One-tailed independent T-test. This test essentially determines if two groups are statistically significant or not significant from each other by testing the difference between the means of the data sets (Trochim, 2006). The reason why the one-tailed T-test is used over the two-tailed T-test is because there is already a presupposition that concentrations of carbon dioxide in bus cabins during rush hour times will be greater than during non-rush hour times.

\section{II.VIII.IV Statistical Package Used}

The statistical packages used will be both Microsoft Office 2013 Excel and NCSS 9: Statistical Analysis and Graphics Program.

\section{II.X.V. Trial Run of Statistical Analysis}

A trial run of statistical analysis was done from the raw data gathered from sample collection. When the data was analyzed using the NCSS 9 program, it can be seen under the "Test of Assumptions" that the normality must be rejected while the variances are accepted. This simply means that non-parametric tests are to be used, particularly the "Mann-Whitney U or Wilcoxon Rank-Sum Test". Under this test, it can be seen that since the P-value was well under the value of 0.05 (i.e. $\mathrm{P}<0.05$ ), there is reason to reject the null hypothesis, which states that there are no significant differences between rush hour and non-rush hour traffic. It must be noted that if the null hypothesis is to be rejected, then there is reason to accept the alternative hypothesis which states that there is statistical significance between the two sets of data. An important point of mention is the possibility of Type I or Type II errors when using inferential statistics. A Type I error can happen when the determined P-value is close to the significance level, thereby leading to 
the null hypothesis being falsely rejected. On the other hand, Type II errors can happen when the null hypothesis is falsely accepted due to the sample size being too small. Since the P-value was well below 0.05 and there were more than thirty samples taken during this analysis, the risk of Type I and Type II errors is relatively low.

\section{Results}

Using the NCSS 9 Statistical software, a one tailed T-test was performed. By first analyzing the section called "Test of Assumptions" in the NCSS 9 program, it was determined that the data was non-parametric. Due to this, the Mann Whitney U/ Wilcoxon Rank Sum statistical test was used and determined that the P-value was well above the alpha level of 0.05 (i.e. $\mathrm{P}<0.05$ ). Since the $\mathrm{P}$ value was above the alpha level of 0.05 , the null hypothesis, which states that concentrations of carbon dioxide within rush hour urban transport microenvironments were not higher than nonrush hour, must be accepted. By accepting the null hypothesis, the alternative hypothesis is rejected, which states that levels of carbon dioxide within rush hour urban transport microenvironments were higher than non-rush hour. The power of the study is also something worthy of mentioning as it determines if the differences between the means were actually different or happened by chance (Dawson \& Trapp, 2004; Leedy \& Ormrod, 2000). Since the power of the study was $16.9 \%$, it can be said that $83.1 \%$ of the statistical analysis results was due to chance. Reasons or factors that may have contributed to such a high degree of chance will be analyzed in the later "Limitations" section of this paper.

\section{Discussion}

Statistical analysis determined that there were no significant differences in the concentrations of carbon dioxide between rush and non-rush hour traffic conditions. This result is contrary to the logic that forms the foundation for the null hypothesis, which states that there are significant differences of carbon dioxide between rush and non-rush hour traffic conditions. As mentioned in the literature review, carbon dioxide comes from both biological and non-biological sources such as from humans and automobile emissions. When there are increasing numbers of humans in such closed environments found in bus cabins during rush hour, it is only logical to infer that there would be a higher concentration of carbon dioxide within these spaces compared to nonrush hour. Several factors observed during analysis that may have contributed to these results will be discussed in greater detail in the following sections.

\section{IV.I. Number of Windows Open during Analysis}

During analysis when windows were open, it caused a drastic decrease in concentrations of carbon dioxide in the sample collection environment. However, this factor was dependent on the weather conditions of the day. For example, when it was a fairly warm day, passengers seemed more inclined to open windows compared to a colder day.

Additionally, rain was also another factor that contributed to the closing of windows. In a study that compared the natural and artificial ventilation of buses in Hong Kong, two key findings were determined: carbon dioxide concentrations were heavily dependent on the number of passengers inside the bus rather than the outdoor air environment and buses that were naturally ventilated had significantly less carbon dioxide than when compared to air conditioned ones (Chan, 2003). This study reflects how opening a window or in other words, naturally ventilating, in the bus cabin will significantly decreases concentrations of carbon dioxide within the cabin.

\section{IV.II. Proximity to Bay Doors during Analysis}

The second factor leading to insignificant results was the location of sample collection during analysis. Again, due to the uncontrollable nature of the study and its intent in staying true to what an average commuter in these urban transport microenvironments would be exposed to, analysis in the same middle location of the bus between the two bay doors was inconsistent at least a small portion of the time. This was especially noticed during particular rush hour conditions when the bus would was too full for analysis in the same 
location. While near the bay doors inside the cabin, it was noticed that small drafts would continue to permeate through and cause an influx of outdoor air to mix with the indoor air environment. This concept was similar to the trickle ventilator mentioned in the indoor air quality study done in schools by Griffiths \& Eftekhari (2007). The level of ventilation of these areas around the bay doors also seemed dependent on the velocity of the bus. For example, when levels of carbon dioxide were high within the bus during rush hour traffic conditions and the bus itself was moving relatively fast, it caused a more noticeable decrease of indoor carbon dioxide concentration than if the bus was moving slower. In the case of commuters, it would generally appear that people who were standing closer to the bay doors were less exposed to higher concentrations of carbon dioxide than compared to commuters that were away from the bay doors.

\section{IV.III. Time of Day during Analysis}

The time of day during analysis also seemed to be a factor in causing varying levels of carbon dioxide. For example, though it was determined that the term "rush hour" pertained to any time in the mornings from 6:00 to 9:30 am and in the afternoons from 3:00 to $6: 30 \mathrm{pm}$ while "non-rush hour" was considered to be any time other than those times, the number of people boarding the bus was varied and inconsistent even within these strict time ranges. In some days during analysis, there would appear to be more people boarding during the non-rush hour time buses than when compared to rush hour time buses, while on other days, there would appear to be less people boarding the rush-hour time buses when compared to nonrush hour time buses. Since it has already been discussed in the literature review that the number of commuters on the bus during the time of analysis is directly related to the increasing concentrations of carbon dioxide in enclosed spaces, it can be inferred that the inconsistent nature of riders during the set ranges of rush hour and non-rush hour traffic times resulted in statistical insignificances between the two sets of data.

\section{IV.IV. Route of Analysis}

In this study, carbon dioxide concentrations during rush hour and non-rush hour traffic times were analyzed between the Cambie and Broadway Skytrain station and the Commercial and Broadway Skytrain station. Every time analysis took place from one Skytrain location to the next, it was considered to be one sample. However, it was noticed that there were significantly more people on board the bus while it was going east bound from Cambie and Broadway to Commercial and Broadway. A possible reason could explain for this trend. Since the majority of commuters taking the 99 B-line may work or go to school in parts west bound of the Cambie and Broadway Skytrain station, it would account for the many commuters going east bound back home during the afternoon rush hour period when the majority of analysis took place. It must be mentioned that due to time constraints, only one rush hour time slot in the afternoon from 3:00 to 6:30 pm could be analyzed at all times. Perhaps if analysis also took place during the rush hour traffic times in the morning as well as in the afternoon, it would have shown that carbon dioxide concentrations were indeed significantly higher than non-rush traffic times. This would account for commuters going to work in rush hour during the morning going west bound from the Commercial and Broadway Skytrain stop as well as commuters going back home east bound from the Cambie and Broadway Skytrain stop. This will be further explained in the limitations section.

\section{IV.V. Location of Sampling during Analysis}

The final factor that may have contributed to insignificant results between rush hour and non-rush hour traffic concentrations of carbon dioxide is the variability of sampling location especially during rush hour times. As already mentioned in the literature review, carbon dioxide in enclosed spaces are not always in steady state concentrations (Seppänen, Fisk \& Mendell., 2004). During times of analysis in rush hour traffic conditions when it could not be controlled where sample collection took place, it was noticed that concentrations of carbon dioxide in the back of the bus were significantly higher than other parts of the bus, assuming the 
majority of windows on the bus was closed.

Firstly, a reason to explain this could be because commuters are deterred from obstructing the driver's view in the front section, thereby disallowing people to gather in high concentrations compared to the back of the bus. Secondly, the middle section of the bus was a location that connected the two carriages of the two section bus together. This section appeared to allow small drafts to come through that may have allowed for a small level of ventilation to be possible, and thereby giving lower levels of carbon dioxide. However, when sampling took place, as commuters are always encouraged to "move to the back of the bus", concentrations of people naturally increased. This would directly result to a higher level of carbon dioxide when compared to the other two sections. Effectively, sampling in this location may have given a biased level of carbon dioxide especially during unexplained increase of commuters during nonrush hour times.

\section{Limitations}

The first limitations to the study was the time constraint that was first realized after the pilot study. Since it was determined that it would take approximately 45 minutes to start from Commercial and Broadway Station to finish at the UBC bus loop, the route of analysis was significantly shortened by changing to the Cambie and Broadway Skytrain station being the end point instead. Though this significantly shortened the time from 45 minutes to 10 minutes, it still proved a challenge to gather a minimum of thirty samples for both rush hour and non-rush hour traffic. The reason for this was because the researcher could not devote all their time into sample analysis due to obligations with work and school. Additionally, due to these obligations, rush hour traffic conditions during the weekday mornings could not be effectively analyzed. This may have caused biased results as mentioned in discussion section above. The second limitation to be discussed is the ability of the instrument.

As already previously mentioned in the literature review and again in the discussion, carbon dioxide does not exist in steady state concentrations. Due to this, the instrument itself could only sample pockets of carbon dioxide during each analysis session. This will inevitably give biased results if there were to be an unusually high or low concentration of people in the immediate surroundings.

The last limitation to be discussed is the inability of the researcher to control certain aspects of the commute. For example, as already mentioned in the discussion, it was at times not possible to get to the middle of the bus to take a sample. Rather, the sample collection would have to take place near the bay doors where it gave biased readings of carbon dioxide.

\section{Conclusion}

Though the literature review determined that the levels of carbon dioxide are positively correlated to the increasing numbers of people in a confined space such as an urban transport microenvironment, this study may have given biased results that contradict this claim. As seen in the results, it was shown that there were no significant differences in carbon dioxide concentrations between rush and non-rush hour traffic conditions. Using these results, one can claim that a commuter in rush hour traffic conditions will be exposed to the same air quality as one in non-rush hour traffic conditions. However, it must be mentioned that the many limitations and variable factors of this study may have led to insignificant results, rather than the data sets actually being insignificant. As mentioned in the discussion, factors like being close to an opened window, where the commuter stands during his/her commute, which section of the bus the commuter is in or simply being in a different route all contribute to varying levels of carbon dioxide extremes. Though the two sets of data were insignificant, it must be mentioned that the averages of both rush and non-rush hour concentrations exceeded the recommended 1000 ppm for indoor carbon dioxide as determined by ASHRAE standards (62-1989). This would effectively mean that both rush and non-rush hour urban transport microenvironments are have poor air quality, regardless of whether it may be significantly different from each other or not. 


\section{Recommendations}

Some recommendations for Translink, the bus company that operates the $99 \mathrm{~B}$-line where sample collection took place, includes installing a better ventilation system into the urban transport microenvironment. Though it was determined that there were no significant differences between rush and non-rush hour traffic carbon dioxide concentrations, it can still be said that it was still well above the recommended levels of $1000 \mathrm{ppm}$ as determined by ASHRAE standards (62-1989). It was noticed that though trickle ventilators were used on the buses analyzed, it still could not effectively decrease levels of carbon dioxide to acceptable levels.

\section{Future Research Suggestions}

Throughout analysis, many

considerations were postulated on how to effectively improve upon this experiment. The problem that should be addressed first is the issue of insignificance between rush and nonrush hour concentrations of carbon dioxide. As mentioned earlier in the discussion section, this insignificance may have been attributed to sampling at inappropriate rush hour times. For example, rush hour in the afternoon going west bound from Commercial and Broadway station was not busy because the majority of commuters were heading home east bound from Cambie and
Broadway station. Therefore, the suggestion is to better define what is to be considered rush hour and non-rush hour times so as to avoid insignificant results.

An obvious limitation to this improved study will be the time constraints associated with being constricted to only one slot of rush hour per day. The second suggestion is to only sample one route of analysis. For example, sampling for rush hour will only take place on the 99 B-line going west bound. The rationale behind this study is so that it only reflects exposure of poor indoor air quality in commuters traveling one way. By doing this, it determines if that specific route has poorer air quality during rush hour than when compared to non-rush hour.

The final recommendation for a future study is to consider analyzing a bus route that is less busy with fewer variances. For example, analysis can take place on a bus route where the researcher can stand in the same location of the bus during the majority of the time. Examples of these less busy routes include the $29^{\text {th }}$ Avenue Skytrain station/ Arbutus route.

\section{Competing Interests}

The authors declare that they have no competing interests. 


\section{References:}

ACGIH. (1971). Carbon dioxide. In: Documentation of the threshold limit values for substances in workroom air. 3rd ed. Cincinnati, OH: American Conference of Governmental Industrial Hygienists, p. 39.

Air Products. (1994). Material safety data sheet \#1005. Retrieved 10/09, 2014, from http://avogadro.chem.iastate.edu/MSDS/carbon_dioxide.pdf

Air Quality Science IAQ Resource Center (Aerias). (2005). Carbon dioxide: A common indoor air pollutant. Retrieved 10/16, 2014, from www.aerias.com

American Society of Heating, Refrigeration and Air-Conditioning Engineers (ASHRAE). (1989): Standards. 62-89: Ventilation for acceptable indoor air quality. Atlanta, GA., USA.

Baek, S. O., Kim, Y. S., \& Perry, R. (1997). Indoor air quality in homes, offices and restaurants in Korean urban areas-indoor/outdoor relationships. Atmospheric Environment, 31(4), 529.

Bourbeau, J., Brisson, C., \& Allaire, S. (1997). Prevalence of the sick building syndrome symptoms in office workers before and six months and three years after being exposed to a building with an improved ventilation system. Occupational and Environmental Medicine, 54, 49.

Brain, M. (2014). How diesel engines work. Retrieved 10/12, 2014, from http://www.howstuffworks.com/diesel1.htm

Chan, A. T. (2003). Commuter exposure and indoor-outdoor relationships of carbon oxides in buses in Hong Kong. Atmospheric Environment, 37(27), 3809-3815.

Dawson, B., \& Trapp, R. G. (2004). Basica and clinical biostatistics (4th ed.) Lange medical books/ Mc Graw-Hill.

Drummond, G. B. (2009). Reporting ethical matters in the journal of physiology: Standards and advice. Journal of Physiology, 587, 713-719.

Griffiths, M., \& Eftekhari, M. (2007). Control of $\mathrm{CO}_{2}$ in a naturally ventilated classroom. Energy and Buildings, 40(4), 556-560.

Goma, A., Guisasola, A., Taya, C., Baeza, J. A., Baeza, M., Bartroli, A., et al. (2010). Benefits of carbon dioxide as $\mathrm{pH}$ reducer in chlorinated indoor swimming pools. Chemosphere, 80(4), 428.

Health Canada. (1987). Exposure guidelines for residential indoor air quality. Retrieved 10/07, 2014, from http://www.hc-sc.gc.ca/ewh-semt/pubs/air/exposure-exposition/index-eng.php 
Hsu, D. J., \& Huang, H. L. (2009). Concentrations of volatile organic compounds, carbon monoxide, carbon dioxide and particulate matter in buses on highways in Taiwan. Atmospheric Environment, 43(36), 5723-5730.

Kaur, S., Nieuwenhuijsen, M. J., \& Colvile, R. N. (2007). Fine particulate matter and carbon dioxide exposure concentrations in urban street transport microenvironments. Atmospheric Environment, 41(23), 4781-4810.

Langford, N. J. (2005). Carbon dioxide poisoning. Toxicological Reviews, 24(4), 229.

Lee, S. C., \& Chang, M. (2000). Indoor and outdoor air quality investigation at schools in Hong Kong. Chemosphere, 41(1-2), 109.

Leedy, P. D., \& Ormrod, J. E. (2000). Practical research: Planning and design (7th ed.) Prentice Hall.

Long, T., \& Johnson, M. (2000). Rigour, reliability and validity in qualitative research. Clinical Effectiveness in Nursing, 4(1), 30-37.

Merriam-Webster. (2014). Dictionary. Retrieved 11/11, 2014, from http://www.merriamwebster.com/dictionary/rush\%20hour

Nelson, L. (2000). Carbon dioxide poisoning. Emerging Medicine, 32(5), 36.

Praxair. (2014). Carbon dioxide. Retrieved 10/12, 2014, from http://www.praxair.com/gases/buy-liquidor-compressed-carbon-dioxide-gas\#!tab=applications

Priestly, M. A. (2003). Respiratory acidosis. Medicine.

Seppanen, O. A., Fisk, W. J., \& Mendell, M. J. (1999). Association of ventilation rates and CO2 concentrations with health and other responses in commercial and institutional buildings. Indoor Air, 9(4), 226-252.

Topham, S., Bazzanella, A., Schiebahn, S., Luhr, S., Zhao, L., Otto, A., et al. (2005). Carbon dioxide. In Wiley-VCH (Ed.), Ullmann's encyclopedia of industrial chemistry (7th ed., pp. 1) Wiley-VCH.

Trochim, W. M. K. (2006). Inferential statistics. Retrieved 11/16, 2014, from http://www.socialresearchmethods.net/kb/statinf.php

US Energy Information Administration. (2014). How much carbon dioxide is produced by burning gasoline and diesel fuel? Retrieved 10/12, 2014, from http://www.eia.gov/tools/faqs/faq.cfm?id=307\&t=11

Washington State Department of Health. (2009). Copper in drinking water. Retrieved 01/10, 2015, from http://www.doh.wa.gov/CommunityandEnvironment/DrinkingWater/Contaminants/Copper

Worksafe BC. (2014). Section 4.79: Investigation. Retrieved 10/12, 2014, from http://www2.worksafebc.com/Publications/OHSRegulation/part4.asp\#SectionNumber:4.70 